\title{
Performance Analysis of an Aircraft Gas Turbine Engine using Particle Swarm Optimization
}

\author{
Jae Won Choi* \\ Department of Aerospace and Mechanical Engineering, Korea Aerospace University, Goyang City, Korea
}

\author{
Hong-Gye Sung** \\ School of Aerospace and Mechanical Engineering, Korea Aerospace University, Goyang City, Korea
}

\begin{abstract}
A turbo fan engine performance analysis and the optimization using particle swarm optimization(PSO) algorithm have been conducted to investigate the effects of major performance design parameters of an aircraft gas turbine engine. The FJ442C turbofan engine, which is widely used in the small business jet, CJ2 has been selected as the basic model. The design parameters consists of the bypass ratio, burner exit temperature, HP compressor ratio, fan inlet mass flow, and nozzle cooling air ratio. The sensitivity analysis of the parameters has been evaluated and the optimization of the parameters has been performed to achieve high net thrust or low specific fuel consumption.
\end{abstract}

Key words: Gas Turbine Engine, Turbo Fan Engine, Particle Swarm Optimization, Net Thrust, Specific Fuel Consumption

\section{Introduction}

The design of aircraft engines is complex as they contain tens of thousands of components. It begins with parametric cycle analysis, which includes the determination of compressors' compression ratios, combustor exit temperature, bypass ratio and so on. It is important to determine the optimization of these parameters which meets customer's requirements like maximization of thrust or minimization of specific fuel consumption in the early phase of engine development. This is because the cost of solving a problem related to the engine design increases exponentially if discovered in the production stage. Many different criteria have been used to evaluate the performance of aircraft engines. For example, Homaifar et al. (1994) used thrust per unit mass flow rate and overall efficiency as the performance measurements and Mach number, compressor pressure ratio, fan pressure ratio, and bypass ratio as key parameters for system optimization of turbofan engine. Asako et al. (2002) employed thrust specific fuel consumption (TSFC) as the performance measurement and high pressure turbine (HPT) efficiency as a key parameter about aircraft engine conceptual design applying multidisciplinary design optimization (MDO). And Atashkari et al. (2005) used TSFC, specific thrust, propulsive efficiency, and thermal efficiency as the engine's performance indicators with regard to thermodynamic Pareto optimization of turbojet engines and considered both two-objective of four indicators and 4-objective optimization processes; this is because they bring an optimized value of an objective or cost function, and single-objective optimization problems have constraint functions on the design variables, and they are considered as constrained optimization problems [1-3].

Concerning optimization algorithm, PSO algorithm is one of the genetic methods used to evaluate birds or insects living in a group and having low intelligence. In the group, each particle has a low intelligence and a simple role, but the
This is an Open Access article distributed under the terms of the Creative Commons Attribution Non-Commercial License (http://creativecommons.org/licenses/by$\mathrm{nc} / 3.0 /$ which permits unrestricted non-commercial use, distribution, and reproduction in any medium, provided the original work is properly cited.

\footnotetext{
(c) * Ph.D. Candidate / currently Senior Researcher in Defense Agency for Technology and Quality

** Professor, Corresponding author: hgsung@kau.ac.kr
} 
synergy of the group's performance is excellent through the common rule and exchanging information. And in the case of low intelligence modeling, computation quantities are significantly reduced as compared with other techniques. The PSO algorithm has the advantages of an ordinary genetic computation's random search performance and search \& converge optimum solution in each revolution stage $[4,5]$. For these reasons, the PSO algorithm has been applied to various optimization studies. For example, Seyed et al. (2012) utilized the PSO algorithm for optimizing thermo-economic analysis of combine gas turbine power plant. And Sadeghierad et al. (2010) performed design of high-speed micro turbine generator which has high rotor speed and high frequency of the stator winding current by using the PSO algorithm for optimizing the efficiency of machine. Weiping et al. (2013) carried out the forecasting of steam turbine heat rate which is important in assuring the economic, efficient, and safe operation by applying PSO algorithm in order to optimize the regularization parameter $r$ and the kernel parameter $\sigma^{2}[6-8]$.

In this research, net thrust and specific fuel consumption (SFC) of gas turbine performance are chosen for the performance indicators. The maximum thrust is related to survivability for a combat mission and the minimizing specific fuel consumption makes more endurance time for a surveillance mission. The turbofan engine performance has optimized values of net thrust and specific fuel consumption when performance parameters such as the bypass ratio, burner exit temperature, high pressure compressor ratio, nozzle cooling air ratio, and fan inlet mass flow are successfully selected. The Gasturb 10 and the PSO algorithm have been employed for this study.

\section{Theoretical Method}

\subsection{Performance Analysis}

A Performance Analysis of the basic turbofan engine has been undertaken by using the Gasturb 10 program. The Basic engine configuration for an analysis model is the FJ44-2C of the small business jet Citation CJ2, developed by Williams International Co. Performance parameters for turbofan engine optimization, illustrates the net thrust and specific fuel consumption.

Figure 1 shows the schematics of FJ44-2C turbofan engine modeling.

In this study, the airstream entering the turbofan engine will flow through the fan and the engine core separately. Cycle analysis is then applied to both the bypass stream and engine core stream separately as listed next. The performance analysis process follows the classical method described in the reference written by Mattingly $[9,10]$.

We consider only the uninstalled thrust $\mathrm{F}$, which depends on the engine alone and hence is independent of the nacelle. Expressed in terms of mass flow rate through fan air stream $\dot{m}_{f}$, the flight Mach number $M_{0}$, sound speed $a_{0}$, velocity $V$, temperature $T$, pressure $P$, and specific heat ratio $\gamma_{c}$, the uninstalled thrust of bypass stream per unit fan air mass flow rate is given by

$$
\frac{F_{f}}{\dot{m}_{f}}=\frac{a_{0}}{g_{c}}\left(\frac{V_{16}}{a_{0}}-M_{0}+\frac{T_{16} / T_{0}}{V_{16} / a_{0}} \frac{1-P_{0} / P_{16}}{\gamma_{c}}\right)
$$

where the number in subscripts represents the location indicated in Fig. 1.

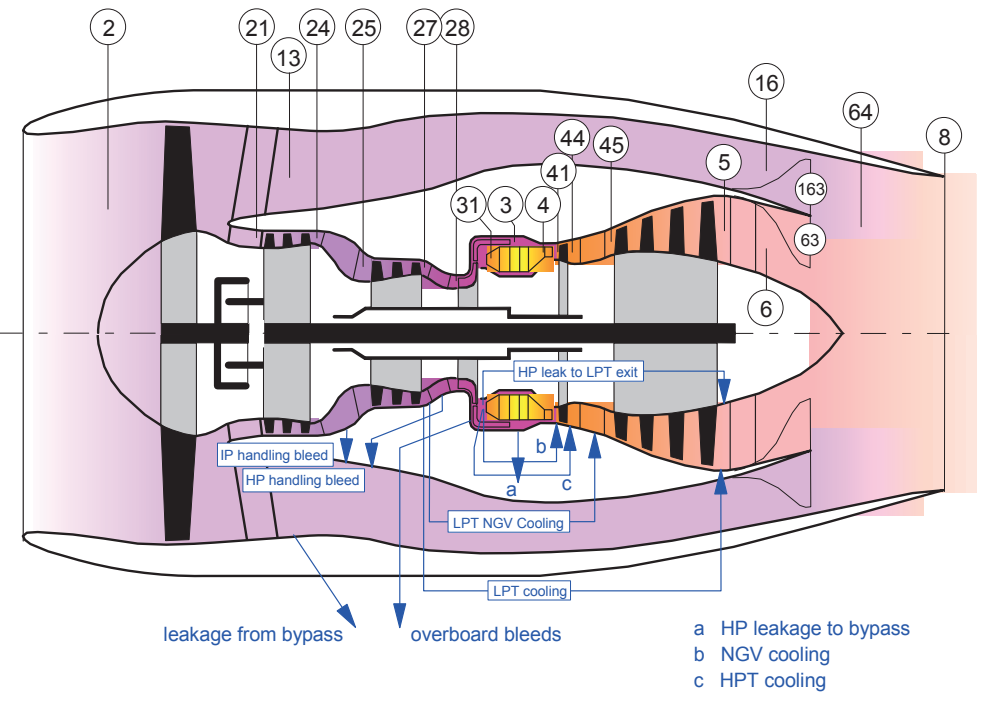

Fig. 1. Engine Schematics for FJ44-2C Cycle Analysis 
The engine core stream cycle analysis is similar to the bypass stream except that it includes energy addition/ subtraction across all components in the engine. The uninstalled thrust of the engine core stream per unit core airflow rate is given by

$$
\left.\frac{F_{c}}{\dot{m}_{c}}=\frac{a_{0}}{g_{c}}\left[(1+f) \frac{V_{16}}{a_{0}}-M_{0}+(1+f) \frac{R_{t}}{R_{c}} \frac{T_{8} / T_{0}}{V_{8} / a_{0}} \frac{1-P_{0} / P_{8}}{\gamma_{c}}\right)\right]
$$

where $f$ is mass flux ratio of fuel to the air through the engine core.

Combining the thrust equations for the fan stream and the engine core stream, the total thrust equation can be demonstrated as follows:

$$
\begin{aligned}
\frac{F}{\dot{m}} & =\frac{1}{1+\alpha} \frac{a_{0}}{g_{c}}\left[(1+f) \frac{V_{8}}{a_{0}}-M_{0}+(1+f) \frac{R_{t}}{R_{c}} \frac{T_{8} / T_{0}}{V_{8} / a_{0}} \frac{1-P_{0} / P_{8}}{\gamma_{c}}\right] \\
& +\frac{\alpha}{1+\alpha} \frac{a_{0}}{g_{c}}\left(\frac{V_{16}}{a_{0}}-M_{0}+\frac{T_{16} / T_{0}}{V_{16} / a_{0}} \frac{1-P_{0} / P_{16}}{\gamma_{c}}\right)
\end{aligned}
$$

The fuel air ratio and specific fuel consumption, $\mathrm{S}$ are demonstrated as follows:

$$
f=\frac{\tau_{\lambda}-\tau_{\gamma} \tau_{c}}{\eta_{b} h_{P R} /\left(C_{p c} T_{0}\right)-\tau_{\lambda}}
$$

$$
S=\frac{f}{(1+\alpha) F / \dot{m}}
$$

\subsection{Optimization}

The PSO employed in this study requires basic mathematical operators, and is computationally inexpensive in terms of both memory requirements and speed, whereas genetic algorithm and simulated annealing techniques take much time to calculate and require a lot of computation resources. Also, if there are sufficient data, PSO can converge the optimization points without a formula of objective functions. PSO usually consists of velocity and position updating formulations which are illustrated as follows:

$$
\begin{aligned}
& v_{i j}(t)=\omega(t) v_{i j}(t-1)+\mathrm{c}_{1} r_{1 j}\left[p_{i j}(t)-x_{i j}(t)\right]+\mathrm{c}_{2} r_{2 j}\left[p_{g i j}(t)-x_{i j}(t)\right] \\
& x_{i}(t+1)=x_{i}(t)+v_{i}(t)
\end{aligned}
$$

$\omega(t)$ in Eq 6 means that the inertia weight and both $c_{1}$ and $c_{2}$ are acceleration constants. $r_{1}$ and $r_{2}$ can get arbitrary values from 0 to 1 . The second term of Eq 6 is a cognitive term and updates partial optimization positions with the experiences of particles themselves. The third is a social

Table 1. FJ44-2C engine basic performance analysis inputs

\begin{tabular}{|c|c|c|}
\hline Parameters & Unit & Value \\
\hline Altitude & $\mathrm{m}$ & 0 \\
\hline Mach Number & & 0 \\
\hline Intake Pressure Ratio & & 1 \\
\hline Inner Fan Pressure Ratio & & 1.3 \\
\hline Outer Fan Pressure Ratio & & 1.5497 \\
\hline IP Comp. Pressure Ratio & & 1.6140 \\
\hline HP Comp. Pressure Ratio & & 6.1001 \\
\hline Design Bypass Ratio & & 3.35 \\
\hline Burner Exit Temperature & $\mathrm{K}$ & $1,378.7$ \\
\hline Burner Design Efficiency & & 0.9994 \\
\hline Fuel Heating Value & $\mathrm{MJ} / \mathrm{kg}$ & 43.124 \\
\hline Overboard Bleed & $\mathrm{kg} / \mathrm{s}$ & 0 \\
\hline Power Offtake & $\mathrm{kW}$ & 0 \\
\hline Burner Pressure Ratio & & 0.9499 \\
\hline Inlet Corr.Flow W2Rstd & $\mathrm{kg} / \mathrm{s}$ & 33.9863 \\
\hline Nominal LP Spool Speed & & 18000 \\
\hline Isentr.Inner LPC Efficiency & & 0.86 \\
\hline Isentr.Outer LPC Efficiency & & 0.87 \\
\hline Nominal HP Spool Speed & & 40,000 \\
\hline Isentr.HPC Efficiency & & 0.79 \\
\hline Isentr.HPT Efficiency & & 0.86 \\
\hline Isentr.LPT Efficiency & & 0.88 \\
\hline & & \\
\hline & & \\
\hline & & \\
\hline & & \\
\hline & & \\
\hline & & \\
\hline & & \\
\hline
\end{tabular}


term and is related to global optimization values. Eq 7 shows the position after a second of $t$, which we can get simply by adding $v_{i}(t)$.

\section{Performance Analysis}

\subsection{On-design performance data}

In accordance with public release, the take-off thrust of the FJ44-2C engine is the same as the maximum continuous thrust of $10.69 \mathrm{kN}$ which is selected as the target value for the performance design as the take-off thrust in this study.

The initial inputs for the analysis are illustrated in Table 1, and Table 2 represents the performance result. The results obtained by employing the performance efficiencies of HPC, LPC, HPT, and LPT listed in Table 1 are very similar to the public released performance [11], which verifies the adaptabilities for a basic performance analysis.

where

LPC : Low Pressure Compressor

IP Compressor : Intermediate Compressor

FHV : Fuel Heating Value (MJ/kg)

FN : Net Thrust (kN)

TSFC : Thrust Specific Fuel Consumption (g/(kg*s))

WF : Fuel Flow (kg/s)

BPR : Bypass Ratio

A8 : Nozzle Area $\left(\mathrm{m}^{2}\right)$

CD : Nozzle Discharge Coefficient
WBLD : Bleed Flow (kg/s)

\subsection{Design performance data evaluation}

In order to conduct properly a performance analysis after analyzing an on-design data of F44-2C turbofan engine, a sub-system performance diagram is necessary for forecasting the sub-system efficiencies in the off-design condition. The ordinary sub-system diagram stacking method multiplies the relevant scaling factors, which are calculated to the design points of new engine, to the original total sub-system data. This method could be quite accurate if the new engines are similar to the reference engines. In this study, the scaling method supplied by the Gasturb model is applied to stacking a similar sub-system performance diagram [11, 12].

$$
\begin{aligned}
& f_{\text {Mass }}=\frac{\left(W \sqrt{\theta_{R}} / \delta\right)_{d p}}{\left(W \sqrt{\theta_{R}} / \delta\right)_{R, \text { map }} \times f_{W, R N I}} \\
& f_{E f f}=\frac{\eta_{d p}}{\eta_{R, \text { map }} \times f_{\eta, R N I}} \\
& f_{P_{3} / P_{2}}=\frac{\left(P_{3} / P_{2}\right)_{d p}-1}{\left(P_{3} / P_{2}\right)_{R, \text { map }}-1} \\
& f_{\text {Speed }}=\frac{1}{N_{R, \text { map }}}
\end{aligned}
$$

where

$$
\begin{aligned}
& W \sqrt{\theta_{R}} / \delta: \text { Corrected Mass Flow } \\
& P_{3} / P_{2}: \text { Pressure Ratio }
\end{aligned}
$$

Table 2. FJ44-2C Design Point Analysis

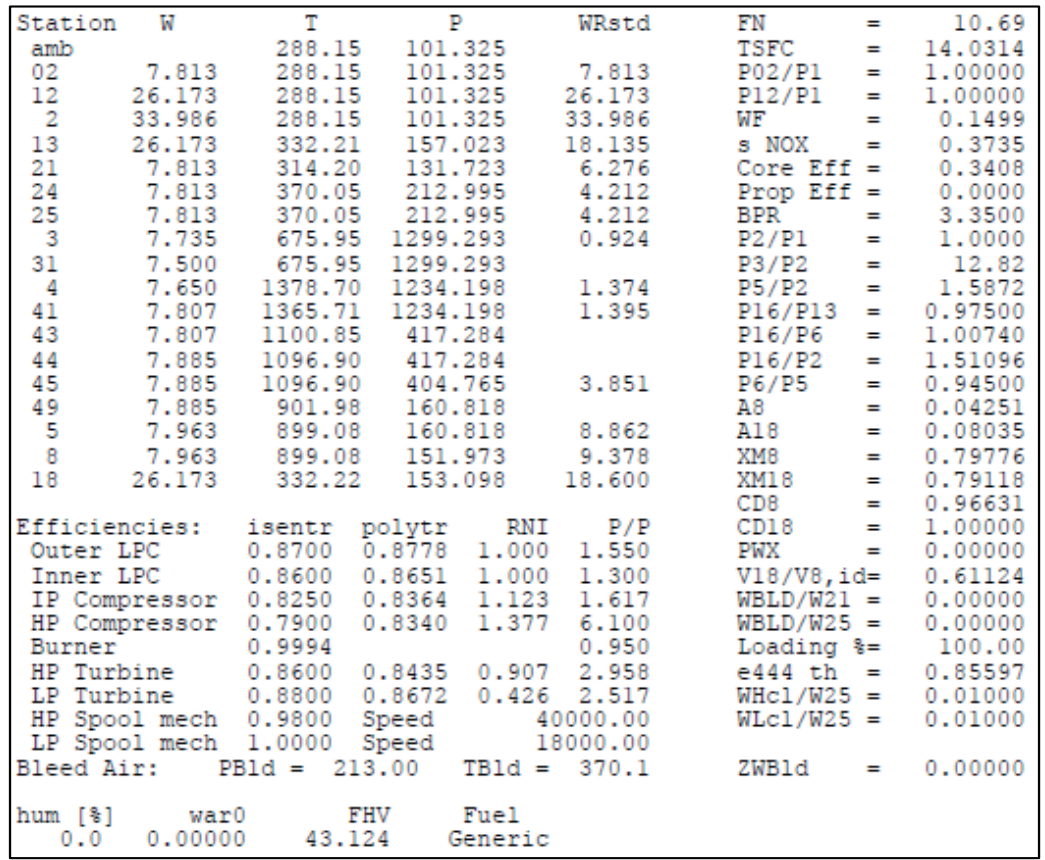


$\eta$ : Efficiency

\section{$N$ : Spool Speed}

$f_{\text {Mass }}$ : Corrected Mass Flow Scaling Factor

$f_{E f f}:$ Efficiency Scaling Factor

$f_{P_{3} / P_{2}}:$ Pressure Ratio Scaling Factor

$f_{\text {Speed }}$ : Corrected Speed Scaling Factor

$f_{W, R N I}$ : Corrected Mass Flow Reynolds Number Effect

$f_{\eta, R N I}$ : Efficiency Reynolds Number Effect

$R$, map : Reference Map

\section{$d p$ : Design Point}

Table 3 compares the off-design analysis results with the basic performance analysis data for net thrust and specific fuel consumption, which shows a maximum difference of $5.88 \%$ for ground and flight altitudes and flight Mach numbers.

\subsection{Performance Analysis}

A performance analysis of parameters is conducted for finding major parameters, which are the bypass ratio, burner exit temperature, HP compressor ratio, fan inlet mass flow, and nozzle cooling air ratio with respect to the basic model of FJ44-2C, having effects on the net thrust and specific fuel consumption. $\mathrm{X}$-axis means the net thrust and $\mathrm{y}$-axis stands for the specific fuel consumption in Fig. 2 through Fig. 5.

Figure 2 shows the case of variations of the bypass ratio from 2.0 to 4.0 with 0.2 intervals and the HP compressor ratio from 4.0 to 8.0 with 0.4 intervals. Increments of the bypass

Table 3. Evaluation of performance data of FJ44-2C

\begin{tabular}{|c|c|c|c|}
\hline Altitude(m) & Speed(M) & $\begin{array}{c}\text { Net Thrust Difference } \\
(\%)\end{array}$ & $\begin{array}{c}\text { SFC Difference } \\
(\%)\end{array}$ \\
\hline 0 & 0 & 0 & 0 \\
\hline 0 & 0.2 & -0.10 & 0.11 \\
\hline 0 & 0.4 & -0.52 & 0.38 \\
\hline 0 & 0.6 & 0.14 & -0.11 \\
\hline 3,000 & 0 & 1.60 & 1.42 \\
\hline 3,000 & 0.2 & 0.97 & 1.95 \\
\hline 3,000 & 0.4 & -0.11 & 2.68 \\
\hline 3,000 & 0.6 & -0.50 & 2.53 \\
\hline 6,000 & 0 & 3.42 & 2.91 \\
\hline 6,000 & 0.2 & 2.67 & 3.51 \\
\hline 6,000 & 0.4 & 1.36 & 4.32 \\
\hline 6,000 & 0.6 & 0.55 & 4.27 \\
\hline 9,000 & 0 & 5.88 & 3.08 \\
\hline 9,000 & 0.2 & 5.21 & 3.65 \\
\hline 9,000 & 0.4 & 4.15 & 4.47 \\
\hline 9,000 & 0.6 & 3.56 & 4.69 \\
\hline
\end{tabular}

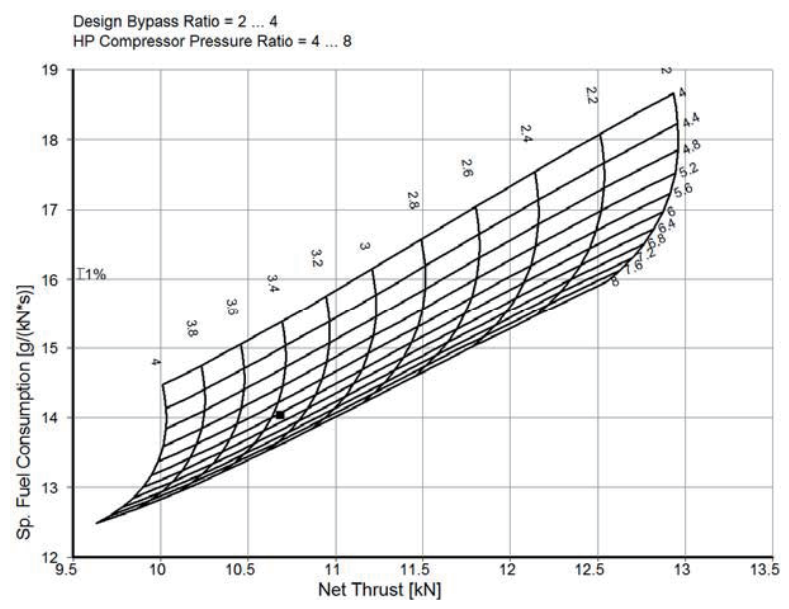

Fig. 2. Specific fuel consumption and net thrust to the bypass ratio vs. HP compressor Ratio

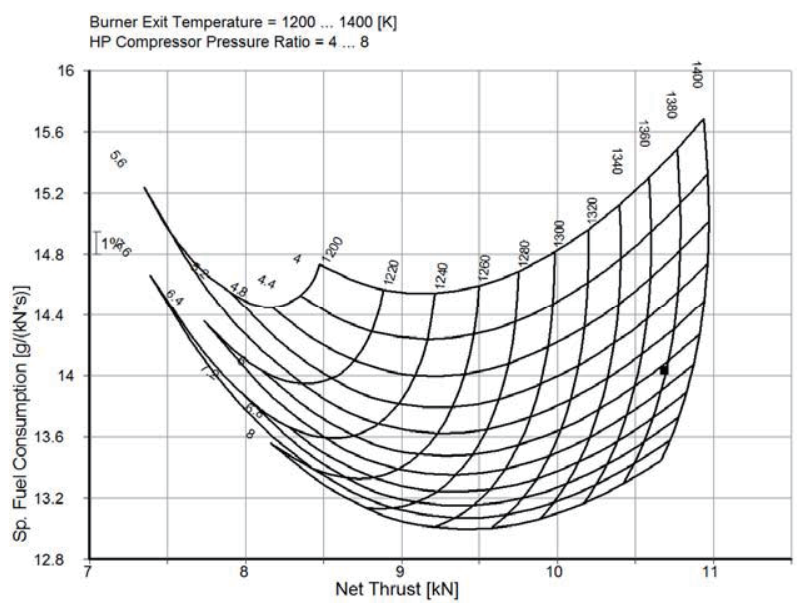

Fig. 3. Specific fuel consumption and net thrust to burner exit temperature Vs. HP compressor ratio 
ratio with respect to the constant HP compressor ratio make positive linear lines in the direction of both the specific fuel consumption and the net thrust lower, and increments of the HP compressor ratio with respect to the constant bypass ratio that looks like parabolic shapes with the maximum net thrust.

Figure 3 shows the case of variations of the burner exit temperature from $1,200 \mathrm{~K}$ to $1,400 \mathrm{~K}$ with 20 intervals and the HP compressor ratio from 4.0 to 8.0 with 0.4 intervals, and increments of the burner exit temperature with respect to the constant HP compressor ratio that looks like bowl shapes with the minimum specific fuel consumption and increments of the HP compressor ratio with respect to the constant burner exit temperature initially make parabolic shapes and change to linear lines.

Figure 4 shows the case of variations of the inlet corrected mass flow from $32.0(\mathrm{~kg} / \mathrm{s})$ to $36.0(\mathrm{~kg} / \mathrm{s})$ with 0.4 intervals and the HP compressor ratio from 4.0 to 8.0 with 0.4 intervals. Increments of the inlet corrected mass flow with respect to the constant HP compressor ratio do not have an effect on the specific fuel consumption and influence only the net thrust, and increments of the HP compressor ratio with respect to the constant inlet corrected mass flow make the similar parabolic shapes with the maximum net thrust.

Figure 5 shows the case of variations of the Nozzle Guide Vane (NGV) cooling air ratio from 0.01 to 0.03 with 0.002 intervals and the HP compressor ratio from 4.0 to 8.0 with 0.4 intervals. Increments of the NGV cooling air ratio with respect to the constant HP compressor ratio make linear lines changing directions, and increments of the inlet corrected mass flow with respect to the constant HP compressor ratio make the parabolic shapes with the maximum net thrust.

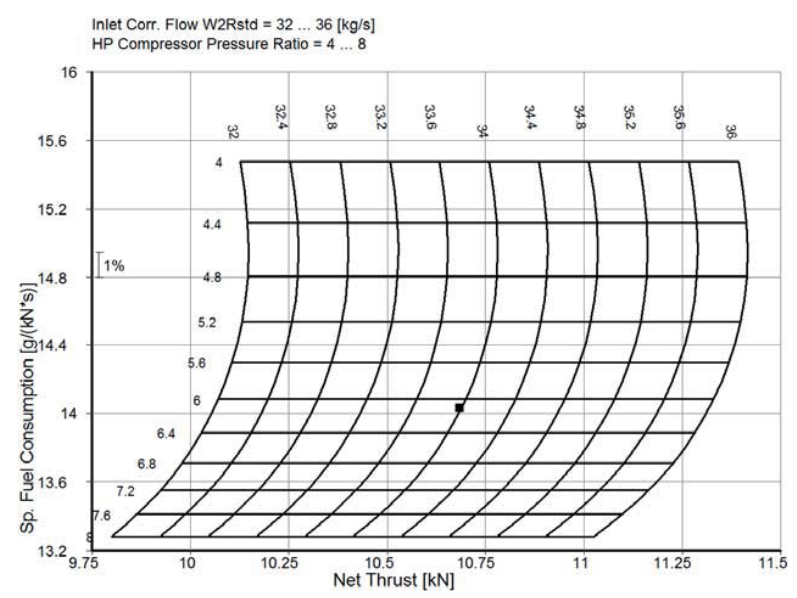

Fig. 4. Specific fuel consumption and net thrust to inlet corrected flow vs. HP compressor ratio

\subsection{Sensitivity Analysis}

A performance optimization is conducted for maximizing the net thrust and minimizing the specific fuel consumption. The critical parameters for optimal design are bypass ratio, burner exit temperature, HP compressor compression ratio, fan inlet mass flow, and the nozzle cooling air ratio etc. When optimizing a turbofan engine performance, one must consider all potential sensitivities of the parameters. The bypass ratio (BPR), burner exit temperature (BET) and HP compressor ratio, and output parameters are set as the major input parameters since the net thrust and specific fuel consumption are not so sensitive to nozzle cooling air ratio. In this study, the OAT (One-at-a-once) Method where one parameter is changing while the other parameters are fixed, is used for sensitivity analysis [13].

Figure 6 shows the One-at-a-once (OAT) analysis results. The gradient rate of change in net thrust is the sequence of bypass ratio, burner exit temperature, HP compressor ratio as of $-0.0004312,0.00147$, and -0.00000660 respectively. The burner exit temperature is the most dominant parameter of the three parameters in the rate of change of the net thrust, and the net thrust increases when the bypass ratio and HP compressor ratio decrease. The gradient rate of change in specific fuel consumption is the sequence of bypass ratio, burner exit temperature, HP compressor ratio as of -0.000154 , 0.0003012 , and -0.0000831 , respectively. The bypass ratio is the most dominant parameter of these three in the rate of change of the specific fuel consumption, and the sensitivity of the HP compressor ratio is much less than that of the others. Also, the specific fuel consumption increases when the burner exit temperature increases.

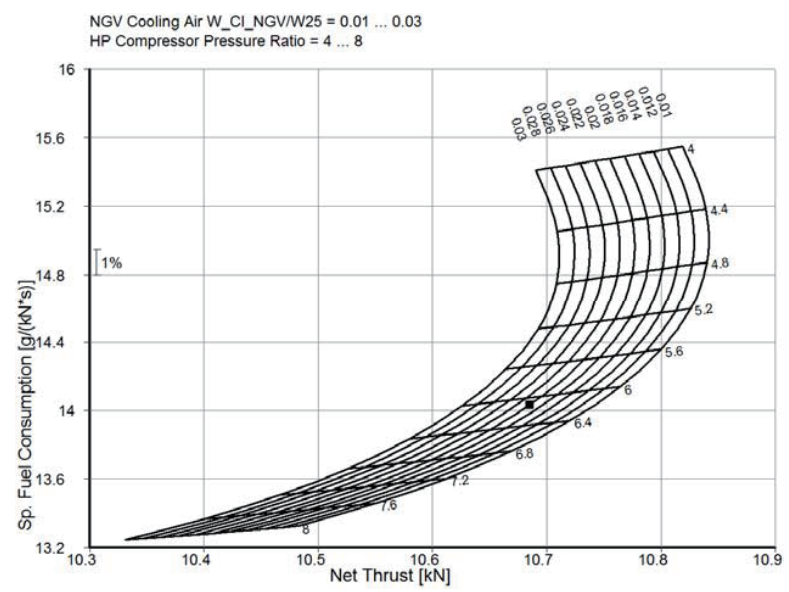

Fig. 5. Specific fuel consumption and net thrust to NGV cooling air ratio vs. HP compressor ratio 

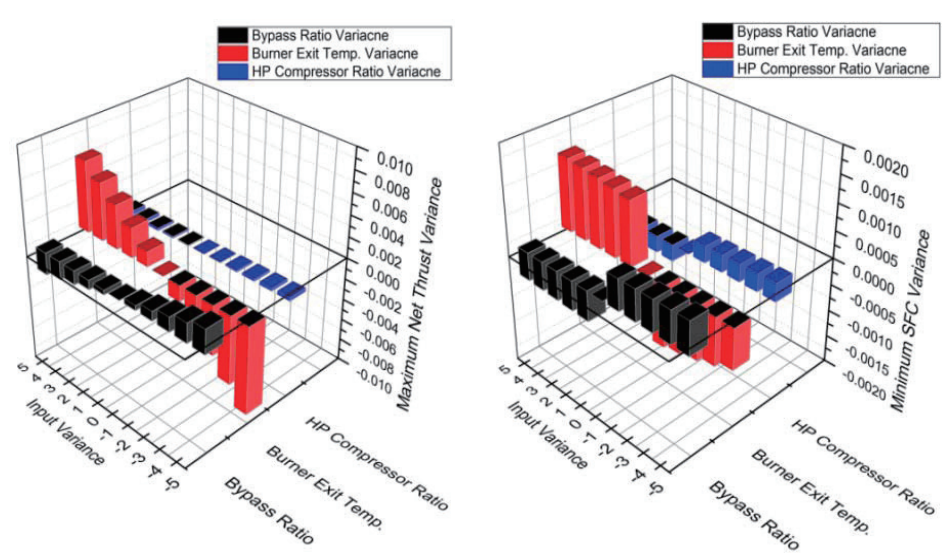

Fig. 6. Sensitivity analysis for bypass ratio, burner exit temperature, and HP compressor ratio

\section{Optimization}

\subsection{Net thrust optimization}

The design parameters can be derived for maximizing net
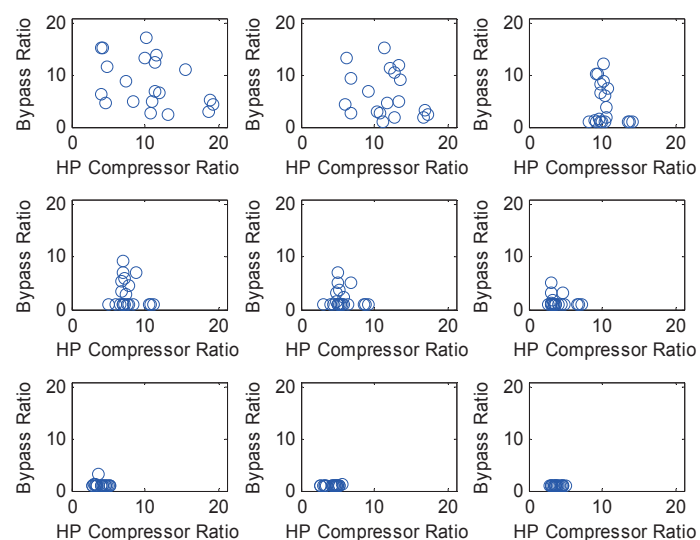

Fig. 7. Net thrust optimization process for bypass ratio vs. HP compressor ratio (case1)

bypass ratio vs. HP compressor ratio (case1)
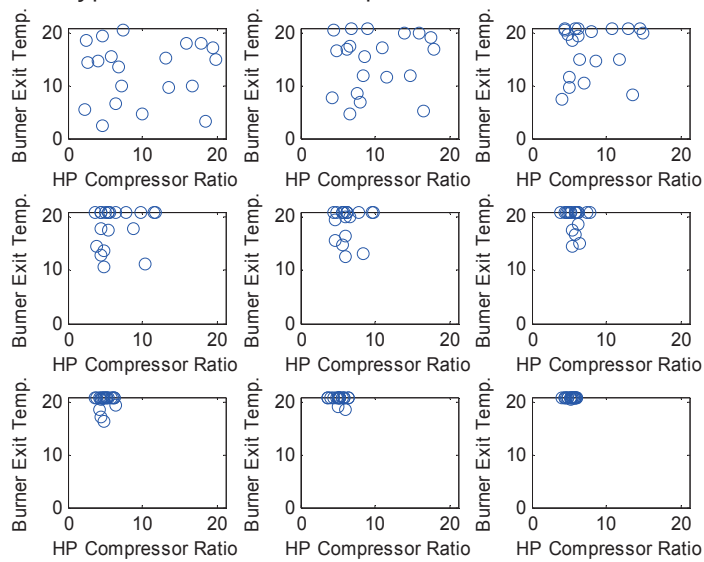

Fig. 8. Net thrust optimization process for burner exit temperature vs. HP compressor ratio (case2) thrust without reference to specific fuel consumption.

Figure 7 through Fig. 10 show the optimized PSO results with respect to the net thrust. Each case calculates 20 times of generations with 20 population size. The axis of
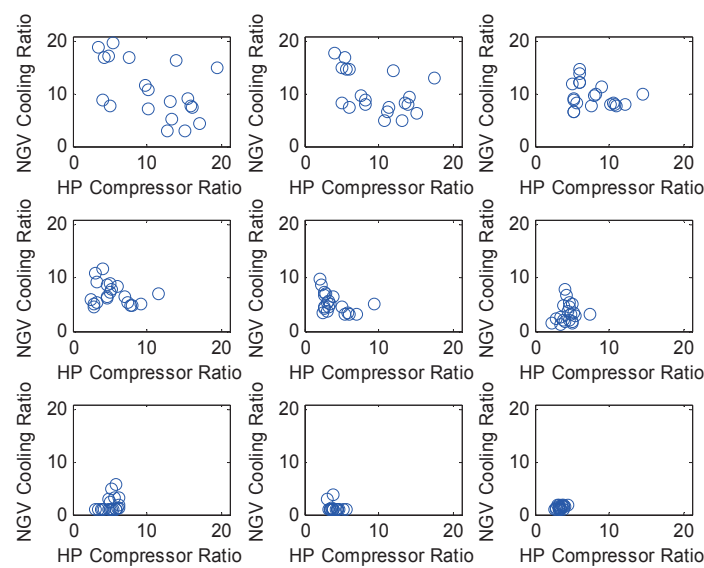

Fig. 9. Net thrust optimization process for NGV cooling air ratio vs. HP compressor ratio(case3)
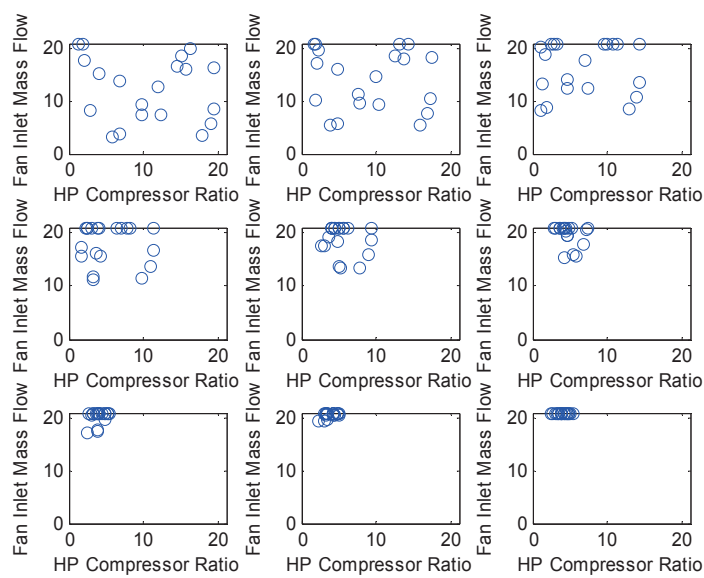

Fig. 10. Net thrust optimization process for fan inlet mass flow vs. HP compressor ratio(case4) 
$x$ means the HP compressor ratio, and the axis of $y$ in Fig. 7 expresses the bypass ratio. Owing to consisting of the results of the optimum net thrust in 21 by 21 matrices, the scopes of the axis of $x$ and $y$ cover 0 thru 21. PSO figures consist of 9 regions. The processes to search the optimum solutions are shown in order from the left-hand sides to the right and from the top to the bottom. The 9 figures show $1^{\text {st }}, 3^{\text {rd }}, 6^{\text {th }}, 9^{\text {th }}, 11^{\text {th }}, 13^{\text {th }}, 15^{\text {th }}, 17^{\text {th }}$, and $19^{\text {th }}$ calculation, respectively. The axis of $y$ in Fig. 8 through 10 means the burner exit temperature, the NGV cooling air ratio, and the fan inlet mass flow. Also, Table 4 through Table 7 show the typical values of the optimization of each case. Case 1 represents the optimum solution between bypass ratio from 2.0 to 4.0 and HP compressor ratio from 4.0 to 8.0. In the same manner, case 2 does optimum solution between burner exit temperature from 1200 to $1400 \mathrm{~K}$ and HP compressor ratio from 4.0 to 8.0. Case 3 does optimum solution between fan inlet cooling air ratio from 32 to 36 and HP compressor ratio from 4.0 to 8.0. Case 4 does optimum solution between NGV cooling air ratio from 0.01

Table 4. Optimum condition of case 1

\begin{tabular}{|c|c|}
\hline Parameters & Value \\
\hline HP Compress ratio & 4.6 \\
\hline Bypass ratio & 2 \\
\hline Net thrust(kN) & 12.9592 \\
\hline
\end{tabular}

Table 5. Optimum condition of case 2

\begin{tabular}{|c|c|}
\hline Parameters & Value \\
\hline HP Compress ratio & 4.8 \\
\hline Burner Exit Temperature(K) & 1400 \\
\hline Net thrust(kN) & 10.9693 \\
\hline
\end{tabular}

Table 6. Optimum condition of case 3

\begin{tabular}{|c|c|}
\hline Parameters & Value \\
\hline HP Compress ratio & 4.6 \\
\hline NGV Cooling Air Ratio & 0.01 \\
\hline Net thrust(kN) & 10.8416 \\
\hline
\end{tabular}

Table 7. Optimum condition of case 4

\begin{tabular}{|c|c|}
\hline Parameters & Value \\
\hline HP Compress ratio & 4.6 \\
\hline Fan Inlet Mass Flow(kg/s) & 36 \\
\hline Net thrust(kN) & 11.4155 \\
\hline
\end{tabular}

to 0.03 and HP compressor ratio from 4.0 to 8.0. Among 4 different cases, we found the net thrust can be increased to a maximum of $21.2 \%$ compared with FJ44-2C basic value $10.69 \mathrm{kN}$ by the bypass ratio and the HP compressor ratio optimized,

\subsection{Specific fuel consumption optimization}

The design parameter can be derived for minimizing specific fuel consumption without reference to net thrust.

Figure 11 through Fig. 14 show the optimized PSO results with respect to the specific fuel consumption. Each case calculates 20 times of generations with 20 population size same as the net thrust optimization. The axis of $x$ in Fig. 11 through Fig. 14 means the high pressure compressor ratio, and the axis of $y$ in Fig. 11 expresses the bypass ratio. PSO figures consist of 9 regions. From the left-hand sides to the right and from the top to the
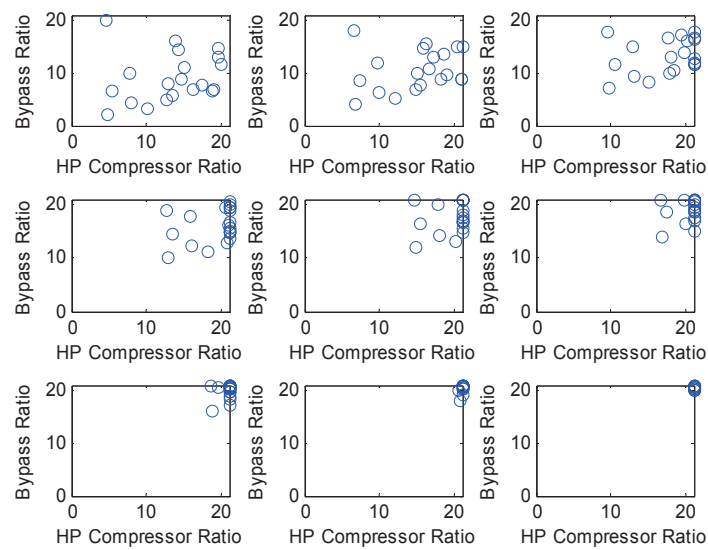

Fig. 11. SFC optimization process for bypass ratio and HP compressor ratio(case 5)
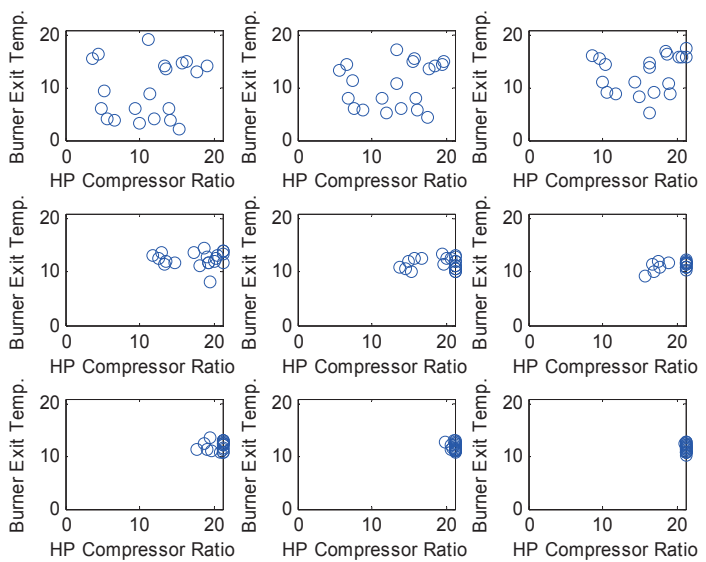

Fig. 12. SFC optimization process for burner exit temperature and HP compressor ratio(case6) 
bottom, they show the processes to search the optimum solutions. The axis of $y$ in Fig. 12 through 14 means the burner exit temperature, the NGV cooling air ratio, and the fan inlet mass flow. Also, Table 8 through Table 11 show the optimized conditions of each case. Case 5 explains the optimum solution between bypass ratio from 2.0 to 4.0 and HP compressor ratio from 4.0 to 8.0. In the same manner, case 6 does optimum solution between burner exit temperature from 1200 to $1400 \mathrm{~K}$ and HP compressor ratio from 4.0 to 8.0. Case 7 does optimum solution between fan inlet cooling air ratio from 32 to 36 and HP compressor ratio from 4.0 to 8.0. Case 8 does optimum solution between NGV cooling air ratio from 0.01 to 0.03 and HP compressor ratio from 4.0 to 8.0. In case of the bypass ratio and the HP compressor ratio optimized among 4 cases, the specific fuel consumption can be reduced to a maximum of $11.0 \%$ compared with FJ44-2C basic value $14.03 \mathrm{~g} /\left(\mathrm{kN}^{*} \mathrm{~s}\right)$.
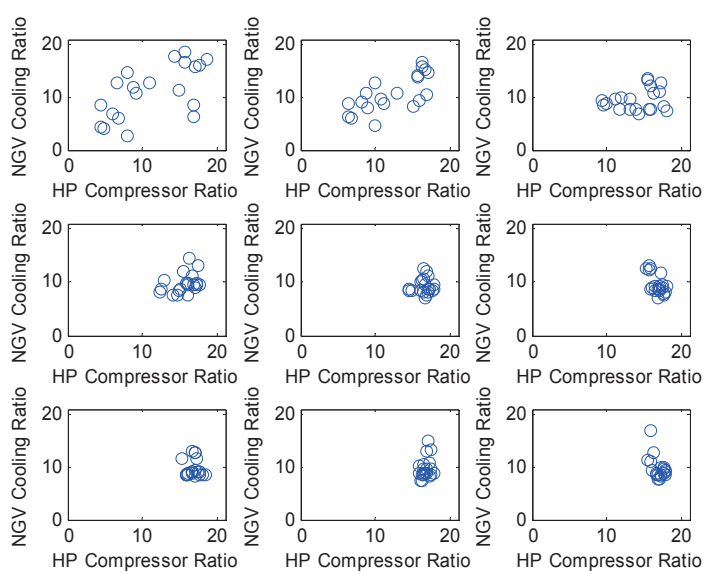

Fig. 13. SFC optimization process for NGV cooling air ratio and HP compressor ratio(case7)
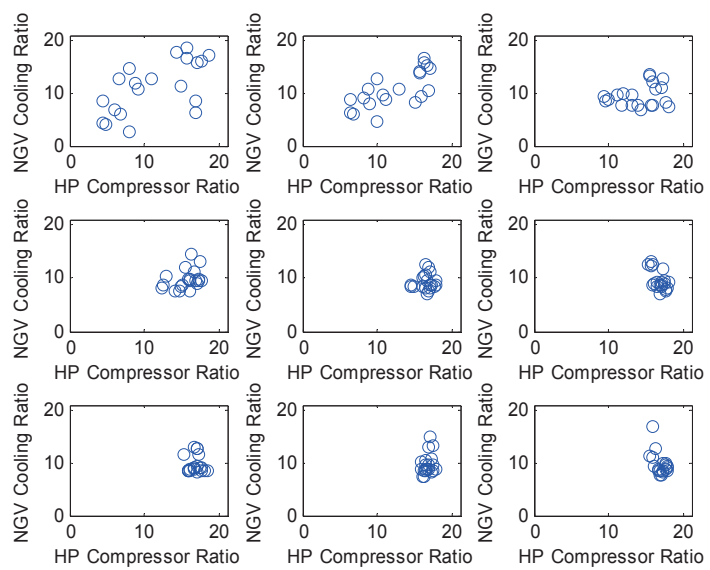

Fig. 14. SFC optimization process for fan inlet mass flow and HP compressor ratio(case8)

\section{Conclusion}

Engine performance analysis and optimization have been conducted to investigate the effect of performance design parameters on net thrust amd specific fuel consumption. Gasturb 10 and particle swarm optimization (PSO) algorithm have been applied to performance ananlysis and the optimization of the FJ44-2C turbofan engine.

The on-design data addressed in this study provide the engine performance favorably fit to the performance data deck of Gasturb 10. Sensitivity analysis results show that burner exit temperature is the dominant parameter in the rate of change of the net thrust, and bypass ratio is the dominant one in the rate of change of the specific fuel consumption.

The PSO algorithm effectively provides the optimized objectives within 20 times of generations with 20 population size. The maximum net thrust can be increased up to $21.2 \%$ or the specific fuel consumption can be reduced up to $11.0 \%$

Table 8. Optimum condition of case 5

\begin{tabular}{|c|c|}
\hline Parameters & Value \\
\hline HP Compressor ratio & 8.0 \\
\hline Bypass ratio & 4 \\
\hline SFC $\left(\mathrm{g} /\left(\mathrm{kN}^{*} \mathrm{~s}\right)\right)$ & 12.4887 \\
\hline
\end{tabular}

Table 9. Optimum condition of case 6

\begin{tabular}{|c|c|}
\hline Parameters & Value \\
\hline HP Compressor ratio & 8.0 \\
\hline Burner Exit Temperature $(\mathrm{K})$ & 1,310 \\
\hline SFC $\left(\mathrm{g} /\left(\mathrm{kN}^{*} \mathrm{~s}\right)\right)$ & 12.9556 \\
\hline
\end{tabular}

Table 10. Optimum condition of case 7

\begin{tabular}{|c|c|}
\hline Parameters & Value \\
\hline HP Compressor ratio & 7.2 \\
\hline NGV Cooling Air Ratio & 0.018 \\
\hline SFC $\left(\mathrm{g} /\left(\mathrm{kN}^{*} \mathrm{~s}\right)\right)$ & 13.5641 \\
\hline
\end{tabular}

Table 11. Optimum condition of case 8

\begin{tabular}{|c|c|}
\hline Parameters & Value \\
\hline HP Compressor ratio & 8 \\
\hline Fan Inlet Mass Flow $(\mathrm{kg} / \mathrm{s})$ & 35.8 \\
\hline SFC $\left(\mathrm{g} /\left(\mathrm{kN}^{*} \mathrm{~s}\right)\right)$ & 13.2838 \\
\hline
\end{tabular}


by the optimized air bypass ratio and HP compression ratio.

\section{Acknowledgement}

This work was supported by Ministry of Trade, Industry and Energy and Korea Aerospace Technology Research Association under the project 10050539.

\section{References}

[1] Homaifar, A., Lai, H.Y and McCormick, E., "System optimization of turbofan engines using genetic algorithms", Applied Mathematical Modelling, 1994, Vol. 18, No. 2, pp.7283.

[2] Asako, T., Miyagawa, H., Miyata, S. and Kudo, K., "Conceptual design of aircraft engine using multidisciplinary design optimization technique", $23^{\text {rd }}$ Congress of International Council of the Aeronautical Sciences, ICAS, 2002, Toronto, Canada.

[3] Atashkari, K., Nariman-Zadeh, N., Pilechi, A., Jamali, A. and Yao, X., "Thermodynamic Pareto optimization of turbojet engines using multi-objective genetic algorithms", International Journal of Thermal Sciences, Vol. 44, No. 11, 2005, pp. 14-24.

[4] J. Kennedy, and R. Eberhart, "Particle Swarm Optimization", Proceedings of IEEE International Conference on Neural Networks, vol. 4, 1995, pp. 1942-1948.

[5] Jin-Eak, Lee., In-Soo, Chun. and Min-Je, Tak., "Midium range flight vehicle optimization of trace using particle swarm optimization", Korea Aerospace Committee, spring conference, 2005, pp. 105-108,

[6] Seyed Ehsan Shakib, Majid Amidpour, and Cyrus Aghanajafi, "Simulation and optimization of multi effect desalination coupled to a gas turbine plant with HRSG consideration", Desalination, 2012, pp. 366-376

[7] M. Sadeghierad, A. Darabi, H. Lesani, and H. Monsef, "Optimal design of the generator of microturbine using genetic algorithm and PSO", Electrical Power and Energy Systems, 2010, PP. 804-808

[8] Weiping Zhang, Peifeng Niu, Guoqiang Li, and Pengfei $\mathrm{Li}$, "Forecasting of turbine heat rate with online least squares support vector machine based on gravitational search algorithm", Knowledge-Based Systems, 2013, pp. 34-44

[9] Jack D. Mattingley, Elements of Gas Turbine Propulsion, McGraw-Hill, 2005

[10] K. H. Liew, E. Urip, and S. L. Yang, "Parametric Cycle Analysis of a Turbofan Engine with an Interstage Turbine Burner," Journal of Propulsion and Power, Vol. 21, No. 3, MayJune 2005, pp.546-551.

[11] Won, Choi., Jae-Ho, Yoo., In-Myun, Chung. And IlWoo, Lee., "A study of gas turbine performance model for aircraft conceptual design", Korea Aerospace Committee, spring conference, 2010.

[12] Won, Choi., Il-Woo, Lee. and Jun-Ho, Yang., "A study of supersonic aircraft low-bypass turbofan engine performance modeling", Korea Aerospace Committee, Vol. 39, No. 3, 2011, pp. 269-278

[13] Czitrom, Veronica, "One-Factor-at-a-Time versus Designed Experiments", Academic journal article from The American Statistician, Vol. 53, No. 2, 1999, pp. 126-131. 